\title{
Analysis of the Relationship between Media and Social System
}

\author{
ZHANG Xiaodong \\ Zaozhuang University Media and Communications of College \\ Shandong Zaozhuang, 277160
}

\begin{abstract}
A perfect social system needs the guarantee and impetus from the advanced media, which refers to the "people's politics" and "people's power". At the same time, the media, as the tool for the interpersonal information exchange, has a positive influence on promoting social democratization. Nowadays, we are in an information society, and the media for transmitting information has become the main link between government and the public. Its social functions of information provider, opinion expresser, public supervisor and so on, can help to improve the public's engagement and participation in their political life. Not only does it meet the diverse needs of both the government and the public, but also integrates the different opinions of people who pursue different benefit. Taking time as the horizontal axis and space as the vertical axis, this paper analyzes the relationship between media evolution, historical progress and institutional modernization, and summarizes their mutual relations.
\end{abstract}

Keywords-Media; Social system; Information; Modernization

\section{INTRODUCTION}

Both the development of human society and the regular running of the state organization can not lack of the dissemination of information. The so-called communication is the transmission of information and the running of social information organization. It basically consists of three essential elements: source of the information, information and sink of information. In the ancient time, people communicate with each other with the direct use of language, and language appears as both the information and the media. With the development of social productive forces, the form of media is changing from original oral communication, paper-based media to nowadays electronic media which appears as internet and satellite communication technology. Media has become an indispensable element of communication.[1]As the lubricant of harmonizing the relationship between the authorities and the public and the communication channel between the government and the social organization, media is becoming more and more significant to keep the society running in right direction.

Media has always been playing an important role in the progress of social democratization. It can be easily recognized that the modernization of media reflects the progressive social democratization.[2]If we take a look at the history of the human beings, we will find that no matter when and where it is, media's function as a tool for human communication takes great effect on the social system in different ways.

\section{Media Evolution AND CHINESE History}

As China has become a major economic power around the world, the modernization of China is drawing attention of the global citizens. It is not only because that China is a country with great amount of culture heritage, but also because that the history of China's media is as typical as its social and national ideology. Development degree of media was an accurate barometer of the social democracy in different period. Media of China is as varied as you can imagine in the country with a history of five thousand years, a population of 1.4 billion and a territory of 9.6 million square kilometers. The following which will review the evolving history of China's media industry will be listed in the order of time.

\section{A. Dynasty of Slavery Society-Xia, Shang and Zhou Dynasty}

During the period of Xia, Shang and Zhou, social productivity was backward. Population in that period is not big. People who lived in that period needed nothing but food to eat. So there was not lot of information needed to spread. What's more, there was not a unified text which could make the information visible. Most of the information was transferred mouth to mouth, and only some important religious and spiritual information could be engraved on the surface of ancient bronze objects or oracle bones.

So the communication need of people during that period was deprived by the basic need of food and clothing. Social democracy has nothing to do with them, not to mention the development of media industry.

\section{B. Spring and Autumn and Warring States Period}

Spring and Autumn Warring States period is period during which the social productivity developed and the population increased fast. Because of the development of material prosperity, culture stepped on the stage. It is called that "a hundred schools of thought contend". Because of the booming of information, media become essential to people who were in badly needs for information and knowledge. But because of the limit of technology, communication still mainly relied on the interpersonal dialogue. Thanks to the unfortunate lucky, the weakening centralization of power made the social position of 
the learned person promoted. People who were professional can travel through different kingdoms to spread their idea and knowledge. Lots of celebrities appeared in this time, like Lao $\mathrm{Zi}$, Confucius, Mo $\mathrm{Zi}$ and so on. They acted as both the source of the information and the media of information.

From the overview of the Spring and Autumn Warring States period, we can found that people in that time had already had the need of communication and the social environment enabled them to receive the information from a teacher or some books. But we can see that books were still expensive and inconvenient. The lack of writing materials and popularizing of unified text made the communication limited. Media's incapability of carrying information seriously influenced the efficiency of communication. In the movie Confucius, the frame in which the students of Confucius lost his life in protecting the bamboo-made books from the rain can reflect the hardness of communication of that time. But it can not be denied that because of the weakening of kingship and the contribution made by the celebrities, the development of media went forward and the people in that time had been inculcated the original idea of advanced forms of society. Social democracy also can be found in the thoughts of Mo Zi, which appears as the political determination of universal love.

\section{Qin Dynasty}

Qin Shihuang, the first emperor in China's history, unified China. Then he unified the measurement and characters. It seemed that all the effort Qin Shihuang made would make the communication between people more convenient and make the culture more flourishing. But the fact is that to consolidate his domination, Qin Shihuang asked his men to burn all of the classical books and to bury alive all the elite scholars. It is undoubtedly a disaster for the communication of art and culture. The source of communication was destroyed and the media for communication was forbidden.

The appearance of Qin Shihuang means the strengthening of the centralization. Communication of culture, art and knowledge had become the privilege of ruling class. Media for communication was developed to some extent, but it was just the tool to preserve their dominance. People who wanted to get information had to get it in some abnormal ways. Media in Qin dynasty made some advance but the Communication among the common people reversed. But the trend of history is that the common people actually need communication to bring them the information which can enrich their spirit and improve their living standard. Lack of communication between the common people and the ruler had also led the society to bad direction. So because of the mismatch of the development degree of media and the development of people's desire for freedom to communicate, people revolted against the rulers finally.

\section{Tang Dynasty}

Tang, the dynasty of which Chinese are highly proud, is the most economically, culturally, politically and militarily prosperous dynasty during the history of China. The history of media industry was also highly developed during this period. First of all, because of the need of transferring decrees and communicating regional affairs, newspaper appeared in the Middle Tang dynasty. Although most of the newspaper was written by hand, it was published regularly and had a standard form. Specific organizations had also been set up to publish the newspaper and there was a specific position for the people who were responsible for the publishing. What's more, because of the flourishing of culture in Tang dynasty, communication between China and other countries frequently occurred especially in the fields of religion and art. For example, the monk, Xuan Zang, travelled to the west and made great contribution to the communication of Buddhism culture between China and other countries. There was a monk called Jian Zhen, who travelled to the opposite direction of Xuan Zang----Japan, and brought great deal of not only Buddhism culture, but also technology and life custom to the local people in Japan. Both of them are the representative figures in the filed of ancient international communication. What's more, the first Chinese female emperor, Wu Zetian, set up a pillar in front of the court.[3] This action allowed all the people to post a note by their own will. As a result, ordinary people could complain about injustices they have sustained and report wrong doings and any official corruption. Then the special organization will be sent on the mission by the emperor which required them to investigate the issue and try their best to give a fair judgment.

The development of media industry resulted from not only the flourishing of culture and economy, but also the political enlightened. Papermaking technology which was invented in Han Dynasty by Cai Lun made paper a widespread material as a convenient carrier of text. Because of Varied kinds of academic schools and different religious belief, it was indispensable that the media industry must move forward. Enrichment of people's knowledge about geography and procession of transportation made it possible to communicate beyond the limit of boundaries. Wu Zetian's achievement---the pillar and posting of a note created a certain degree of freedom of expression in Tan dynasty for the first time in China's history. Development of media industry produced by the imperial power which mainly was for the sake of the political aims, politics has been deepened step by step with interfering with. It has produced counteraction conversely to the imperial power.

\section{E. Song Dynasty}

During the Song dynasty, China witnessed a higher urbanization level, more prosperous commerce and international trade, and an explosion of technical inventions and institutional innovations, and the development and improvement of printing was one of the great technical inventions. Despite the fact that China lost a significant amount of arable land to invading nomads as its population peaked, it was obviously that common people in Song dynasty lived a richer life compared to people who lived in other dynasties. We can get the information from the famous picture---Riverside Scene of Pure Brightness which has a high historical value. It is commonly believed that China's budding capitalist first appeared in Song dynasty. During Song dynasty, media industry made its progress in faster speed. At some prosperous regions like the capital---Bianjing, tabloid came into people's sight and staked its claim in the market which used to be totally dominated by the government newspaper. Common people 
started to gain information of the upper classes, and information was no longer the exclusive content of the rulers.

Tabloid is a miniature of the media industry in Song dynasty. It reflected the decline of the imperial power and the raise of people's living standards. The development and papermaking technology and the improvement of printing make the hardware condition of media industry more and more complete and convenient. The cost of communication tools became lower and affordable to the common people. What's more, the rise of pop culture and perfection of the culture of elitism provided the media with the great amount of communication content. In the other hand, due to the weakness of centralization, the curtailing of freedom of expression didn't make sense in the limitation of different opinions towards the authorities. Common people can express their opinion freely and needed not to worry about punishment. A "Free Market" of opinion had emerged and it seemed that the spring of media had drawn near.

\section{F. Ming Dynasty and Qing Dynasty}

The last two dynasties in China's history, Ming and Qing, are two stagnant dynasties which have a sharp contrast compared to Song dynasty. The high centralization of power and the high curtailing of freedom of expression limit the development of communication freedom. On the development of China, China found itself induced deeper into the economy and culture trap, resulting in reduced urbanization, withering foreign trade, a declining division of labor, and stagnant in technology. Of course, media industry can not go against the tide of history. Because of the control of national minority rulers of Yuan and Qing, the Han culture was deeply broken and the tradition of culture communication bogged down.

\section{G. Modern China}

Modern China was a semi-colonial and semi-feudal state until the foundation of the People's Republic of China (PRC). The state's political situation was unstable, the flames of war raged everywhere, both the ruling classes and the ruled couldn't live through as they used to. Economy and culture rose and fell with the condition of the state. Social formation during this period evolved dramatically, people in this time had widely accepted the idea of democracy and freedom. Media industry played an important role on this historical stage. After the "Xinhai" revolutionin1911, there was a short period of increased media freedom. During this time, varied kinds of books and newspapers were allowed to be published. Media freedom expanded throughout the "Xinhai" revolution. However, after eight years, May Fourth movement, also called the Civil War Movement, broke out in China. The media industry once again exhibited difficulties during that time. Because of the suppression of the army government, the May Fourth Movement failed to achieve its original goal of returning the city of Qingdao and having the right of media freedom. However, the May Fourth Movement demonstrated that the Chinese people had the ability to successfully struggle and improve the nation with better ideals and it paved the way for the development of rudimental media freedom and political democracy.
After the foundation of People's Republic of China, all the Chinese participated in the building of a new China. The spread of knowledge among the farmers made the mass media work. And the mass media also contributed to improve the people's quality. During that period, different kinds of opinions and varied academic schools sprung out across the land of China.

Media industry in nowadays China has a new role in the society with China's continued economic development in the new century. It not only served as a symbol of social democracy, but also provided platform for Chinese people to discuss and debate over political issues and economic events. Since China's recent reform, the media industry has been greatly influenced by the global community. After years of efforts of trying to adapt to the international community, Chinese media system has evolved into its own entity. Currently, There is much media freedom including the freedom to advertise, freedom to promote ideas and the freedom to critique local government officials. There is also freedom to disseminate news.

In summary, the development of media industry of China during the history of China can reflect the social improvement from the ancient feudal regimes to today's China. Due to China's explosive economic development, the research of China's media industry doubtlessly has momentous meaning. It is not only the study of relationship between media modernization and social democracy, but also a miniature of the evolution of whole the human beings' media industry. Based on the view of different social forms and economic foundation, we can summarize that the trends of media modernization versus social democracy are almost the same. In a less technical way, media modernization and social democracy benefit each other and promote each other.

\section{MEDIA INDUSTRY IN MODERN SOCIETY}

As television, radio, telephone, desktop computer, game console and handheld device are widely used in people's daily life, media industry today has become a time of electric media. People all over the world are connected by the Internet, and they share their ideas and express their opinions with the help of social networking system. It is the Web2.0 that dominate the internet with the superiority of participation, creation and

The following content will discuss the media industry in different regions in nowaday world and find out the relationship between the development standard of the local media industry and the local social democracy. Three examples which happened recently in different regions will be given.

\section{A. The Effect of Media Modernization on Social Change in Middle-East and North Africa}

The history of media industry in Middle-East and North Africa is generally short, but develops rapidly. The development of media industry in different country in MiddleEast and North Africa is unbalanced but is relatively lagged behind as a whole. Media industry has a close relationship with politics especially in Middle-East. Recently, a series of democratic movement broke up across the nations in MiddleEast and North Africa, such as Tunisia, Egypt, Syria, Jordan, 
Yemen, and Bahrain and so on. The movement is still going on till today and social media is playing a significant role during the whole process. Out of the social media, Facebook and Twitter are the most characteristic modern social network systems which are pushing the democratic uprisings forward. These series of movements is called the Arab Spring.

\section{B. The Effect of Media Modernization on Presidential Election in US}

The presidential election in the US reflects the developed democratic political system. It is an effective way for the public to indicate their political position and enjoy their civic rights. Modern media's effect on the election reflects its promotion on the social democracy.

In the 2008 U.S. presidential election, the campaign of Obama established a central network, and managed it effectively. It was their successful management of the modern electric media that helped them defeat other candidates.

Firstly, Obama and his voters "has always been together" by the use of various kinds of new social network, such as Myspace, Facebook, Faithbase, video-sharing site You Tube, photo-sharing site FlickR, content-sharing site Digg. It seemed that Obama was everywhere. Myspace allows the users to mark the presidential candidates as their friends. This behavior shortened the distance between the candidates and the voters. Obama has four hundred thousand friends on Myspace and 1.2 million supporters on Facebook. Both of Hillary and Obama created their own personal pages, but Obama got One hundred and fifty thousand followers while Hillary got only six thousand followers. The difference between two of them is that Obama had interaction with the followers and positively followed his followers, while Hillary did not. During this process, the new social media was not only a information publishing platform, but also a tool to let your followers fell your existence. Common people and the candidates grasped the world together, shared their feeling, watched the same movie and listened to the same song. Finally, Obama got along with his voters and won the presidency. Taking full advantage of the modern media, The Obama team has provided us with some valuable strategies and tactics.

It can be summarized that the modern social media has a great influence on the society. Meanwhile, the mass media has in every aspect penetrated into the society just like air wandering around us and make people willing to be part of it. With the help of modern mass media, the key individual nowhere is absent and all pervasive, and behaving very actively. What's more, the modern media puts the real life and the online life together with the guidance of the expanded function of opinion leaders. All of these have made it possible to build a democratic world with the spirit of common resolve.

\section{The Effect of Modern Media on the Social Supervision in China}

Micro blogging tools like Twitter and Weibo have become one of the fastest ways to disseminate a message to the greatest number of people. This story is not new in China but it is still interesting. Last year, a scandal broke out after Chinese citizens discovered a 20 year old lady named Guo Meimei Baby, was allegedly spending Red Cross Society of China (RCSC) donation money on lavish luxury items like a Maserati sports car. The controversy has landed CRSC, China's biggest charity organization in a lot of trouble after heated allegations of corruption. Guo Meimei labeled her Weibo account as the Commercial General Manager of the China Red Cross Chamber of Commerce. Weibo users than started to wonder what her connection was with CSRC and if she was misusing public donations on herself. After damaged credibility, RCSC has tried to appease the public by approving national audits and investigations relating to insider corruption.

On Weibo, internet users would thoroughly oversee what you say and what you do, therefore, there won't be any room for any false stories, lies or fabrications. In this sense, Weibo is no longer a channel of personal consolation or expressing of personal feelings. It also has become a comprehensive form of involving even with social issues and civic development issues of the country for the public. We cannot underestimate the probability of Weibo power. Now, more and more news are reported out of the Weibo first. The news starts not from the media but among the people. The public can see the development of the changes and in a way supervised the handling of the events and their resolutions. Weibo mainly is very popular among youngsters. It's quite sure Weibo will affect the younger generation in their thoughts, attitudes and enthusiastic participations in social issues. On Weibo, everyone has opportunities to express as if it's their common platform. And there are also great positive aspects where people could change current political and social environments. The public express their opinions and the government listens to them. According to the public platform and communication mechanisms on Weibo, the country and the society could become more harmonious. Weibo also needs public's effective guidance for the healthy, long-term development for its continually growing role in modern society.

\section{InNOVATIVE USES OF MODERn SOCIAL MEDiA}

As we have seen, some of the most innovative uses of modern social media for civic engagement and social change come from social movement participants, organizations and networks. There is no doubt that modernized media playing a vital part in promoting the development of social democracy by its effect on social change, social choice and social supervision. But the social network system like Facebook, Twitter or Weibo still needs to overcome its short-comings. There is still a lot of obstacles lying on the road to democracy. It is excited enough because the social democracy is on the way and it will be realized someday by the self-perfection of the modernized media.[4] 


\section{CONCLUSION}

In summary, history has showed us that modernization of media has promoted the social democracy in a general positive direction. A few cases in recent years has confirmed that modernized social media is a powerful weapon in the struggle of social democracy. Significant role played by the modernized media in various major respects: facilitating participatory journalism which reflects a new form of public sphere, enhancing social interaction and social integration which include information sharing, resources integration and social bond consolidation, as well as formulating a platform for community-reviving and collective identity-reinforcing. The impact and role of media in social democracy is worthy of reorganization. It is closely connected with the degree of development of the entire social economy and politics. But the expanded effect of the modernized media can not be ignored. Correct understanding of the role of media in the promotion and improvement of social democracy is essential. Modernized media gives the public the power to participate in the social affairs. So the problem how we should make better use of the new facilities is placed in front of everyone living in this world.

\section{REFERENCES}

[1] Understanding Media [M]. Yilin Publishing House, (Canada) Mcluhan (McLuhan, 2011).

[2] Social Thought Master [M]. Shanghai People's Publishing House, (USA) Kose (Coser, 2007).

[3] The Political Function of the Ancient Media "Lubu": [J]. Zhao Yunze, Chu hang. News spring and autumn. 2017 (01).

[4] Lonely Crowd [M]. Nanjing University Press, (USA) David Resman (DavidRiesman) et al., 2002. 